\section{Fraud in science}

SIR,-Surprisingly, in the article by Mr Larry Altman and $\mathrm{Mr}$ Laurie Melcher (25 June, $p$ 2003) and in the correspondence that followed ( 30 July, p 355), no mention has been made of "the Sobell affair." Dr Mark and Dr Linda Sobell conducted the most widely known and quoted trial of controlled drinking treatment for alcoholics at Patton State Hospital, San Bernadino, California in the early 1970s. Their follow up results suggested that their controlled drinking programme was superior to traditional treatment directed at total abstinence, and there is no doubt that their work greatly increased interest in the possibility of offering a controlled drinking treatment goal to alcoholics. ${ }^{2}$

More recently, an article in the magazine Science by Dr Mary L Pendery, Professor Irving M Maltzman, and Professor L Jolyon West, in conjunction with a draft of the same article, which was widely circulated among those treating and researching alcoholism, has been generally interpreted as accusing the Sobells of fraud ${ }^{3}$ and, indeed, such an accusation has been clearly attributed to Professor Maltzman in reports of the affair in American newspapers. On 6 March 1983 the Sobells' integrity was again called into question in the highly popular CBS documentary programme 60 Minutes. My fear is that, as details of the Sobell affair become more widely known in Britain, it will simply be assumed that it is yet another instance in the recent spate of frauds in clinical research described by $\mathrm{Mr}$ Altman and $\mathrm{Mr}$ Melcher. In fact, there are important differences.

In the first place, despite an initially widespread assumption of their guilt, the Sobells have now been cleared of fraud by an independent committee of inquiry convened by the president of the Alcoholism and Drug Addiction Research Foundation in Toronto, where the Sobells are now employed. This committee was chaired by Bernard M Dickens, professor of law, criminology, and community health at the University of Toronto, and its other members were all distinguished and highly respected scientists and scholars. The verdict of the Dickens' report, published in November $1982,{ }^{4}$ has been subsequently confirmed by a special investigator appointed by the United States House of Representatives Subcommittee on Oversights and Investigations Although more may be heard of this unhappy business and other inquiries may possibly take place, it is obvious that the case against the Sobells is far from proved.

Thus, on the same principle that all that glitters is not gold, it should always be remembered that not all who have been accused of fraud, even by eminent members of the scientific community, have in fact commited it. Further, all who have been accused should be given an automatic and immediate right of reply, which did not happen in this case; the Sobells would have had no knowledge of the impending Science article had not a friend warned them shortly before, and they were refused the opportunity to comment on the article in the same issue. This led to a letter of protest to Science from 10 editors of clinical and research journals. ${ }^{5}$

Of course, the Sobell affair cannot be seen in isolation but must be regarded as the latest battle in the fierce ideological war that has been waged over the issue of controlled drinking among former alcoholics ever since the possibility was first raised by the late $\mathrm{Dr} \mathrm{D} \mathrm{L}$
Davies in $1962 .{ }^{6}$ The same is no doubt true of other accusations of fraud, and they must all be placed in the social and political context in which they occur. Although Mr Altman and $\mathrm{Mr}$ Melcher are undoubtedly right to demand from scientists a higher degree of vigilance and openness to the danger of fraud, it is essential that we remain as critical as possible in assessing every allegation.

\section{Nick HeAtheR}

Department of Psychiatry, Ninewells Hospital, Dundee DD19SY

' Sobell MB, Sobell LC. Behavioural treatment of alcoholic problems. New York: Plenum Press, 1978.
Heather N, Robertson I. Controlled drinking (revised Heather N, Robertson I. Controlled drinking (revised edition). London and New York: Methuen (in
press). press).

drinking by alcoholics? New fint LJ. Controlled drinking by alcoholics? New findings and a reevaluation of a
$1982 ; 217: 169-75$

- Dickens BM, chairman. Report of the committee of enquiry into allegations concerning Drs Linda and
Mark Sobell. Toronto: Addiction Research Foundation, 1983.

Barlow DH, Bellack AS, Buchwald AM, et al. Alcoholism studies. Science 1983;220:554.

addicts. Quarterly dournal of in recorded alcoho addicts. Quarterly

\section{Informed consent}

SIR,-The discussion in these columns about informed consent has raised an important question. Whose attitudes to informed consent are most important - those of doctors, lawyers, "ethicists," or patients? As one doctor has already pointed out,' we have heard a lot on the subject from the first three, but unfortunately we know virtually nothing on the attitude of patients.

The few systematic investigations that have been conducted suggest, firstly, that patients vary in the extent to which they wish to receive information about the risks associated with their treatment, ${ }^{2}$ and, secondly, that they want to play a part in deciding the amount of information they receive (18 June, $p$ 1972). These findings are unlikely to surprise most of those who either deliver or receive good clinical care.

It is against this background that we are left speculating about the possible implications for clinical practice of the high sounding but non-specific invocation of Nuremberg by an "ethicist" like Dr Huw Francis (6 August, p 430). We assume that Dr Francis agrees with our own view that patients should always be at liberty to decline any of the treatments offered to them. But can we assume that he would also agree with us that patients should be free to decide the extent to which they should be informed about the basis on which their treatment has been selected and, in addition, about the conceivable risks associated with this and alternative treatments?

As potential patients we have a vested interest in this matter. We wish to be treated by doctors who are not subject to authoritarian strictures that attempt to standardise the way they communicate with their patients about selection and risks of treatment. We do not wish, for example, to receive an unsolicited and sadistic rehearsal of all the risks associated with alternative treatments for acute myocardial infarction as we are wheeled into the coronary care unit. Nor do we wish any malignan process from which we may be suffering to be potentiated by stress ${ }^{3}$ caused by a clinician who has been forced by "ethicists" to override cues intended to indicate when we have heard enough.
Those who brandish Nuremberg (and, by implication, Auschwitz) in the confident certainty that an insistence on "fully informed consent to treatment" will protect individual patients should consider the implications of their injunctions more carefully. As has been pointed out before, the possible consequences of the informed consent ritual range from "minor annoyance to, in extreme cases, death." "

IAIN Chalmers ADRIAN GRANT

National Perinatal Epidemiology Unit,

Radcliffe Infirmary,
Oxford OX2 $6 \mathrm{HE}$

Baum M. Fashion versus facts: the case for clinical trials. World Medicine 1983;19:36.

L ankton JW, Batchelder BM, Ominsky AJ. Emotional responses to detailed risk disclosure for anaesthesia a prospective, randomised study. Anesthesiology $1977 ; 46: 294-6$ Papaioannou A. Informed consent after randomisa-
tion. Lancet $1982 ; 1 i: 828$.

hazardous to health. Informed consent may be

***This correspondence is now closed.-ED, $B M 7$.

\section{Spinal disease presenting as acute} abdominal pain

SIR, - The sequence of events reported by $\mathrm{Mr}$ R Jooma and others (9 July, p 117), particularly that of their first case report, is unfortunately all too common. We report here a further three cases of spinal infection referred to this unit within the past three months. All three patients were adults with a mean age of 57 ; two were diabetics; and the mean time from initial presentation to surgical decompression was four months (the longest interval was 11 months, in a 58 year old woman with diabetes). In one patient the diagnosis of spinal infection was not suspected, and the other two were undergoing investigations for a spinal neoplasm. The radiological features of spinal infection and neoplasm are, however, differentially diagnostic. ${ }^{1}$ In spinal infection there is narrowing of a disc space with destruction of the contiguous margins of the adjacent vertebral bodies, while in neoplasm there is destruction of the vertebral body with preservation of the discs above and below.

It is worrying, however, that some surgeons still seek to decompress a spinal infection frem the back when the disease, and source of spinal cord compression, is anterior. This has been known for more than 50 years and led to the now standard anterior approach to the spine for spinal infection complicated by either abscess formation or paraplegia or both. ${ }^{2}{ }^{4}$ The posterior aspect of the dura is under tension and further compresses the cord against the abscess or local kyphosis." Accordingly, "laminectomy is not only futile but actually harmful" as the only structures of integrity are the posterior ele.nents. Despite a wealth of recent published reports condemning laminectomy ${ }^{7-10}$ it is still unfortunately being performed.

Spinal infections may be managed conservatively provided that the organism is known and that there is no abscess formation or neurological signs. The correct management for patients with neurological signs or in whom the spinal cord is compressed from the front, is anterior decompression and strut grafting. ${ }^{2+611}$ Although two of our three patients have made an uneventful recovery, 